\title{
EL ENEDUDAMIENTO LOCAL EN LOS MUNICIPIOS ESPAÑOLES. SITUACIÓN ACTUAL Y ALTERNATIVAS
}

\section{LOCAL INSUFFICIENCY IN SPANISH MUNICIPALITIES. CURRENT SITUATION AND ALTERNATIVES}

\author{
Maravillas I. Abadía Jover \\ Funcionaria Local con Habilitación Nacional Ayuntamiento de Alcantarilla \\ E-mail: maravillasabadia@ayto-alcantarilla.es
}

Convidada

RESUMEN: El endeudamiento de las Administraciones Públicas ocupa en la actualidad una posición relevante en el ámbito de estudio de la Hacienda Pública, debido esencialmente a la situación de crisis económica y a las necesidades financieras públicas. El gasto local impropio financiado en buena medida con recursos ajenos, ha conllevado a un aumento de la deuda local. En la actualidad, la expansión natural de los servicios impropios es insostenible y de proseguir esta tendencia las Corporaciones locales se enfrentarán de nuevo a situaciones de insuficiencia financiera aún más complicadas.

En este orden de cosas, dada la necesidad de las Entidades locales de prestar dichos servicios públicos y ante la situación de insuficiencia financiera de sus haciendas, ha sido el interés por estudiar el endeudamiento de las Administraciones Públicas, tratando de establecer las principales variantes que afectan al endeudamiento, constatando con datos empíricos la realidad existente y planteando las posibles alternativas al endeudamiento, en aras al cumplimiento de la obligación fundamental de cualquier Administración, como es la de satisfacer las necesidades de sus ciudadanos.

Palabras Clave: Endeudamiento, estabilidad presupuestaria, sostenibilidad financiera, deuda pública, fuentes de financiación.

\begin{abstract}
The indebtedness of Public Administrations currently occupies a relevant position in the field of study of the Public Treasury, due essentially to the situation of economic crisis and public financial needs. Improper local spending, financed largely with outside resources, has led to an increase in local debt. Currently, the natural expansion of improper services is unsustainable and if this trend continues, local Corporations will again face situations of even more complicated financial insufficiency.

In this order of things, given the need of local entities to provide such public services and in the face of the financial insufficiency of their haciendas, has been the interest to study the indebtedness of the Public Administrations, trying to establish the main variants that affect to indebtedness, confirming with empirical data the existing reality and proposing the possible alternatives to indebtedness, in order to fulfill the fundamental obligation of any Administration, such as satisfying the needs of its citizens.
\end{abstract}

Keywords: Indebtedness, budgetary stability, financial sustainability, public debt, sources of financing. 
SUMÁRIO: Prenotandos; 1. El endedudamiento local en el Marco Estatal, autonómico y local; 2. Evoluciónhistórica; 3. Especial referencia a lasalternativas al endeudamiento; Conclusiones; Bibliografía.

\section{PRENOTANDOS}

En los últimos tiempos, el endeudamiento constituye uno de los temas más preocupantes en el ámbito local, habida cuenta que muchos municipios tienen que acudir a esta vía, ante la insuficiencia financiera ${ }^{1}$ que acucia a las Haciendas Locales, para satisfacer las necesidades de sus vecinos y ello es debido a diferentes causas de las cuales podemos resaltar dos de ellas que se consideran como principales. En primer lugar, al descenso generalizado de ingresos tributarios debido a la caída de la actividad económica en general y de la actividad urbanística en particular que reportaba pingües beneficios a los municipios. En segundo lugar, las Entidades locales se ven compelidas, en aras del cumplimiento del principio de subsidiaridad y en el marco del Estado Social consagrado en el artículo 1 de nuestra Carta Magna ${ }^{2}$, a prestar un amplio número de servicios públicos que son reclamados por la población, al ser la organización más próxima al ciudadano. En algunos casos, estos servicios prestados por las Entidades locales constituyen servicios impropios, esto es, de titularidad de otras Administraciones Públicas.

Esta situación ha llevado a la mayoría de los municipios a incrementar considerablemente el endeudamiento, siendo posible asegurar que la mayoría de las Corporaciones locales podrían estar actualmente en el límite máximo posible de endeudamiento. A ello se añade, la perspectiva futura de subidas del tipo de interés que introduce un factor adicional de riesgo en situaciones de alto apalancamiento financiero.

Ante esta situación y dado que la imposición local está ligada en buena medida al sector inmobiliario, una desaceleración importante de éste, como ha sucedido actualmente, podría exigir un ajuste severo del gasto local o bien plantear otra alternativa que parece más conveniente que estaría relacionada con la necesidad de dotar de mayores recursos al sistema de financiación local, puesto que es éste nivel, el local, el más directo para los ciudadanos.

Para hacer frente, por tanto, a la situación actual de las Administraciones Locales es necesario reducir el gasto público local o aumentar los ingresos. La reducción del gasto no es sencilla pues existe una elevada rigidez en los gastos locales, lo cual implica la dificultad en su reducción si bien es posible minorarlos en cierta cuantía. La elevación de los ingresos corrientes es complicada, pues los ingresos tributarios actuales han descendido considerablemente y no se espera todavía un nuevo sistema de financiación local que abogue por una mayor dotación de recursos a las Entidades locales. Por ello, una de las posibilidades de financiación por parte de la Administración local consiste en acudir al endeudamiento concertando operaciones de crédito, obviando, por tanto, la vía tributaria como forma de financiación.

En este panorama, los municipios han elevado considerablemente su nivel de endeudamiento y al análisis del mismo se dedica este trabajo. La economía española no ha sido ajena a las necesidades de la política económica y, en atención a la misma, ha mantenido unos niveles de endeudamiento que procedemos a comparar entre el año 2004 y el año 2012. Se ha elegido este período de manera principal, con el objetivo de proceder a analizar los resultados obtenidos antes y después de la crisis económica.

${ }^{1}$ El principio de suficienciafinancieravieneplasmado en nuestraCarta Magna. No obstante, esmásunaaspiraciónqueunarealidadyaque hoy en díaesprecisoformular planes de estabilidadparaquelasEntidades Locales alcancen el anheladosuperávit o déficit cero. El fin de Tesorería cero implicabuscar la constantesincronización de lascorrientes de cobros y pagos en fechavalor.

${ }^{2}$ El artículo 1.1 de la Constitución Española disponeque "España se constituye en un Estado social y democrático de Derecho, quepropugnacomovaloressuperiores de suordenamientojurídico la libertad, la justicia, la igualdad y el pluralismopolítico". 


\section{EL ENDEDUDAMIENTO LOCAL EN EL MARCO ESTATAL, AUTONÓMICO Y LOCAL}

Antes de realizar con mayor detenimiento un análisis del endeudamiento local, lo pondremos en relación con el endeudamiento estatal, autonómico y local.

En este contexto, es importante conocer cuál es la participación de cada uno de las estructuras en las cuales se divide la organización territorial del Estado en España. Por ello, a continuación, se muestra la deuda en circulación de las Administraciones Públicas, en porcentaje del PIB, desglosando según se trata de la Administración central, de las Comunidades Autónomas, de las Corporaciones locales o de la Administración de la Seguridad Social.

En el siguiente cuadro, se puede comprobar cómo es la Administración central la que mayor participación tiene en el total de deuda pública:

Cuadro I. Deudaencirculación de lasAdministraciones Públicas. Distribución institucional. Porcentajedel PIB. Años 2004-2013.

\begin{tabular}{|l|l|l|l|l|l|l|}
\hline \multicolumn{1}{|c|}{ AÑ } & TOTAL & CENTRAL & \multicolumn{1}{c|}{ CCAA } & CCLL & S. SOCIAL & $\begin{array}{c}\text { PIB } \\
\text { Millones } \boldsymbol{\epsilon}\end{array}$ \\
\hline $\mathbf{0 4}$ & 46,3 & 39,4 & 6,2 & 2,9 & 2,2 & 841.294 \\
\hline $\mathbf{0 5}$ & 43,2 & 36,4 & 6,4 & 2,8 & 2,0 & 909.298 \\
\hline $\mathbf{0 6}$ & 39,7 & 33,0 & 6,0 & 2,8 & 1,8 & 985.547 \\
\hline $\mathbf{0 7}$ & 36,3 & 30,1 & 5,8 & 2,8 & 1,6 & 1.053 .161 \\
\hline $\mathbf{0 8}$ & 40,2 & 33,7 & 6,7 & 2,9 & 1,6 & 1.087 .788 \\
\hline $\mathbf{0 9}$ & 54,0 & 46,4 & 8,7 & 3,3 & 1,6 & 1.046 .894 \\
\hline $\mathbf{1 0}$ IV & 61,7 & 52,6 & 11,6 & 3,4 & 1,6 & 1.045 .620 \\
\hline $\mathbf{1 1}$ I & 65,6 & 55,6 & 12,2 & 3,6 & 1,6 & 1.047 .239 \\
\hline II & 67,3 & 56,7 & 13,0 & 3,6 & 1,6 & 1.049 .275 \\
\hline III & 67,6 & 57,0 & 13,2 & 3,5 & 1,6 & 1.050 .094 \\
\hline IV & 70,5 & 59,5 & 13,6 & 3,4 & 1,6 & 1.046 .327 \\
\hline $\mathbf{1 2}$ I & 74,4 & 62,8 & 14,1 & 3,5 & 1,6 & 1.042 .779 \\
\hline II & 77,6 & 65,5 & 16,3 & 4,3 & 1,7 & 1.037 .907 \\
\hline III & 79,1 & 67,2 & 16,3 & 4,2 & 1,7 & 1.034 .345 \\
\hline IV & 86,0 & 73,9 & 18,0 & 4,1 & 1,7 & 1.029 .002 \\
\hline $\mathbf{1 3}$ I & 90,0 & 77,7 & 18,6 & 4,2 & 1,7 & 1.025 .870 \\
\hline II & 92,2 & 80,0 & 19,0 & 4,2 & 1,7 & 1.023 .086 \\
\hline III & 93,4 & 81,3 & 19,3 & 4,1 & 1,7 & 1.022 .496 \\
\hline
\end{tabular}

Fuente: Banco de España. 
En el siguiente gráfico podemos comprobar la evolución a lo largo de estos años:

Gráfico I. Evolución de ladeuda/PIB enlasAdministraciones Públicas. Porcentajedel PIB. Años 2004-2012.

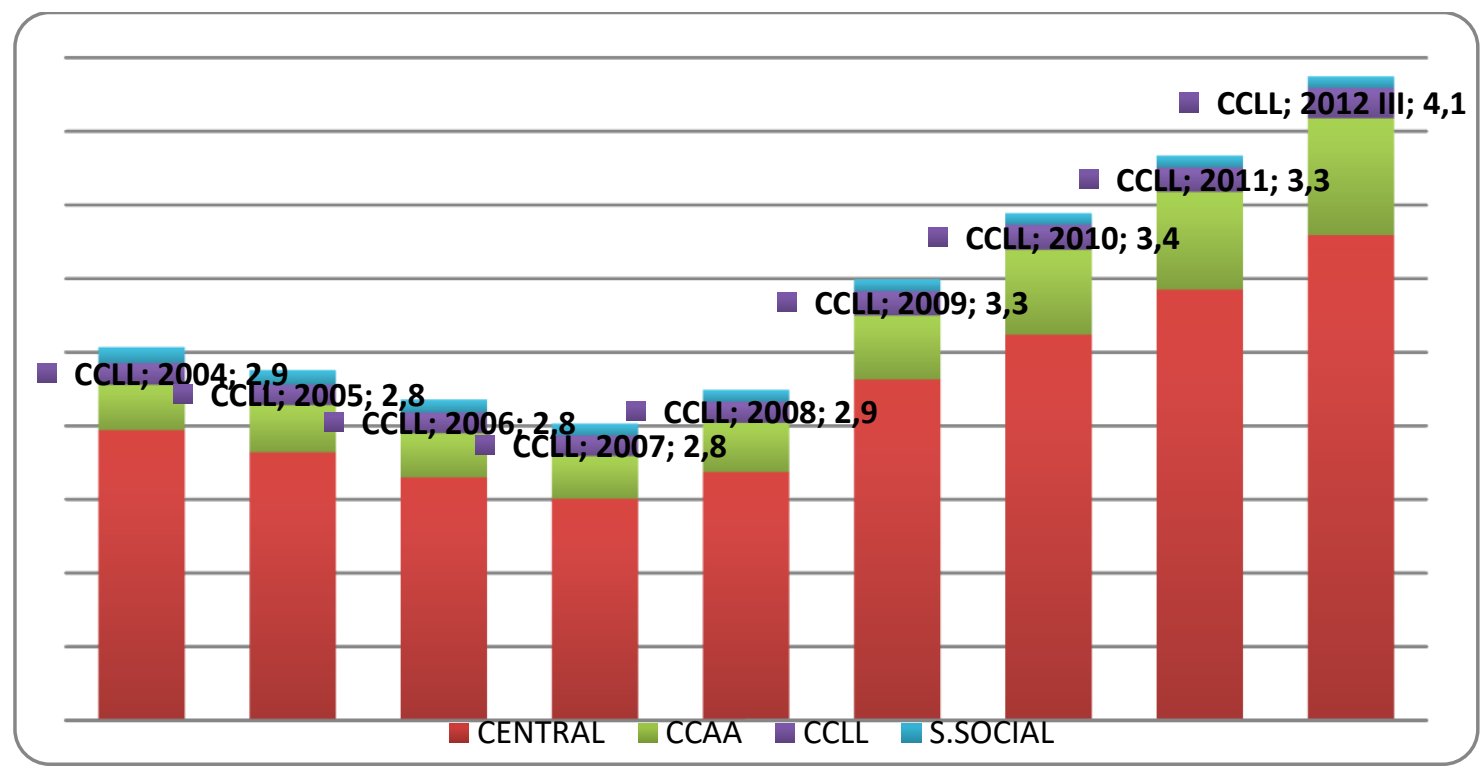

Fuente: Banco de España y elaboración propia.

Las Entidades locales no han incrementado sustancialmente su nivel de deuda/PIBpues han pasado de suponer el 2,9 por cien en 2004 a representar el 4,1 por cien en los años 2012 y 2013, un crecimiento exiguo si lo comparamos con el que se ha producido en las Comunidades Autónomas y el Estado, si bien es necesario tener en cuenta el menor peso de las Entidades locales en el conjunto de las Administraciones Públicas. En efecto, las autonomías suponían en 2004 el 6,2 por cien y en 2013 han incrementado su participación hasta el 19,3 por cien. Por su parte, el Estado, que en 2004 presentaba un valor del 39,4 por cien supone el 81,3 por cien en 2013. Es decir, han sido principalmente las Comunidades Autónomas y el Estado los que han incrementado considerablemente la ratio deuda /PIB a lo largo del período analizado.

Resulta de interés conocer la composición de la deuda a lo largo de los años analizados, la cual se muestra en el siguiente gráfico: 
Gráfico II. Composición de ladeudaencirculación de lasAdministraciones Públicas. Porcentajes. Años 2004-2012.

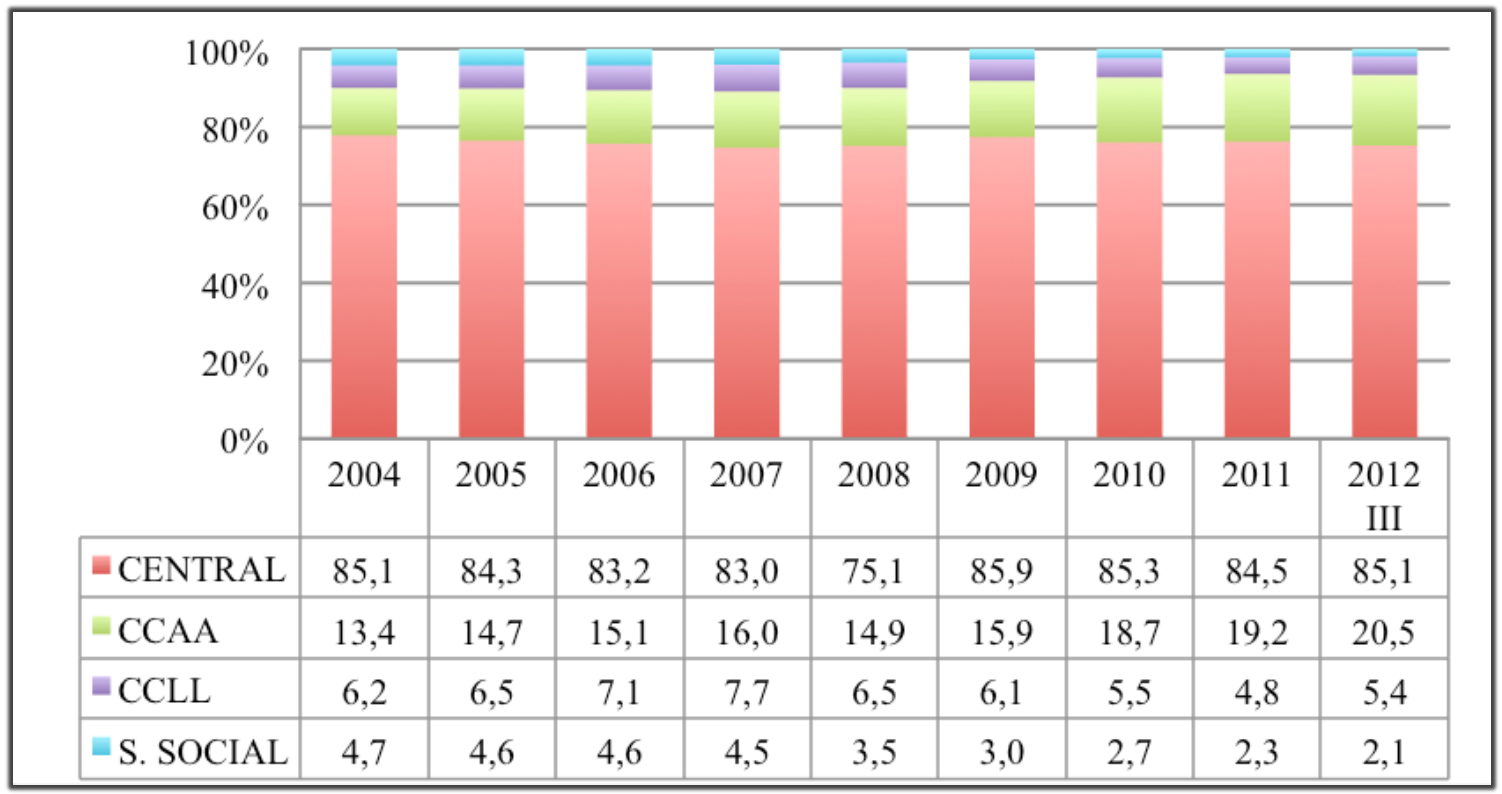

Fuente: Banco de España y elaboración propia.

Mientras que las Corporaciones locales tienen una mayor representación en el total al principio del período considerado - el 6,2 por cien - van reduciendo su participación en el total de la deuda para ir aumentando su participación las autonomías, lo cual demuestra una vez más la desigualdad en la descentralización territorial del Estado en los últimos años.

Tras esta visión de la situación actual del endeudamiento local, pasamos a continuación a realizar un análisis de la evolución histórica del mismo.

\section{EVOLUCIÓN HISTÓRICA}

En la actualidad, los ayuntamientos españoles se encuentran inmersos en un periodo de cambios normativos sustanciales, motivados fundamentalmente, por los efectos de la Ley de Estabilidad Presupuestaria y Sostenibilidad Financiera o por la reforma de la financiación local, todo lo cual plantea un nuevo contexto plagado de incertidumbres que aconsejan realizar un balance de la situación en que se encuentra la Hacienda municipal iniciando el estudio a través de la evolución histórica del endeudamiento local.

Los ayuntamientos españoles arrastran una deuda histórica cada vez mayor. En este sentido, el déficit de las Haciendas locales fue especialmente alarmante en la década de los ochenta, puesto que es precisamente en esa época cuando se empieza a recurrir al crédito como mecanismo de financiación, ya que es el instrumento que más se conoce como recurso financiero y, al mismo tiempo, el más desconocido desde la perspectiva del ciudadano medio, hasta la llegada de la Ley Reguladora de las Haciendas Locales, con la que se comienza a reducir el déficit. Durante los años 70 y 80, el sistema financiero sufría una gran crisis de liquidez. Ello, unido a la iniciativa por parte de las Entidades locales de realizar inversiones, impedía la materialización de las mismas acudiendo a la vía del endeudamiento. Durante esos años, la financiación provenía casi siempre de la banca pública y como nota característica no de una entidad financiera sino de la agrupación de varias. Como características de ésta época hay que destacar las siguientes:

- Carencia de transparencia en la regulación de los intereses.

- Preferencia de las Entidades locales de acudir a la vía de la autofinanciación. 
Sin embargo, la situación en 1983 se volvió insostenible para la Hacienda local y el Gobierno tuvo que improvisar unas medidas urgentes, aglutinadas en la Ley 24/1983, de 21 de diciembre, de Medidas Urgentes de Saneamiento y Regulación de las Haciendas Locales. Esta ley se promulgó con la intención de sanear el nivel local de gobierno, como solución provisional previa a la anhelada reforma y modernización de las Entidades Locales. Para tratar de paliar esta situación, el legislador consideró tres objetivos fundamentales:

1) La nivelación financiera. Para ello, el Estado, se comprometía a asumir el déficit local a 31 de diciembre de 1982.

2) La eliminación de las causas del déficit, creando un sistema de tutela estatal sobre el gasto local de las Entidades locales que libremente se quisieran acoger a los mecanismos de saneamiento financiero previstos en la Ley, y

3) La suficiencia y autonomía financiera. Se permitió a los Ayuntamientos establecer un recargo sobre la cuota líquida del Impuesto sobre la renta de las personas físicas y se cedió potestad normativa para la fijación del tipo impositivo de las Contribuciones Territorial Urbana (CTU) y Rústica y Pecuaria (CTR).

No obstante, el mecanismo más importante e innovador de la Ley de Medidas Urgentes fue declarado inconstitucional, lo que neutralizó el potencial recaudador esperado. Sin embargo, el Estado se subrogó en las deudas locales y estableció un mecanismo de control del gasto local.

De ésta manera, cuando se implantó la Ley 39/1988, Reguladora de las Haciendas Locales, las Corporaciones municipales soportaban, una vez más, un elevado nivel de endeudamiento, unido a una elevada carga financiera.

La nueva Ley basó la financiación local sobre dos pilares fundamentales: tributos propios y participación en los ingresos del Estado ${ }^{3}$.

A pesar del nuevo modelo de financiación local, la crisis financiera local que tuvo lugar durante los años 1990-1995 tuvo como causas de la misma las siguientes ${ }^{4}$ :

- La deuda pública local se concentró en el corto y medio plazo

- Los altos tipos de interés existentes en ese momento en el sistema financiero, fatídico para el sector local.

- Las restricciones legales al endeudamiento local y la rigidez introducida en la gestión de tesorería que obligaba a exigentes ajustes presupuestarios.

- El deseo local de alcanzar una cuota de participación del $25 \%$ del gasto público total. Esta ilusión, tras la entrada en vigor de la Ley 39/1988, reguladora de las Haciendas locales, desembocó en aumentos del gasto local y en la recurrencia al crédito, bajo la creencia de la existencia de una garantía implícita del Estado para la cobertura del riesgo inherente.

- La expansión de los servicios públicos municipales más allá de los niveles mínimos exigidos por la legislación básica del régimen local.

Los ajustes presupuestarios realizados por las Corporaciones locales permitieron una salida rápida de la crisis fiscal. A ello contribuyeron, sin duda, una serie de factores positivos que acaecieron a partir de 1994, entre los cuales podemos destacar el descenso del interés básico del Banco de España, que permitió aliviar la carga financiera y la refinanciación de la deuda local en mejores condiciones que en la década de los ochenta, con un tipo de interés menor y mayores plazos de amortización.

\footnotetext{
${ }^{3}$ En realidad, la participación en los ingresosdel Estado es la principal fuente de financiación de lasEntidades locales, enmarcadadentro de la modalidad de transferenciascorrientes de carácterincondicional.

${ }^{4}$ Undesarrollomásexhaustivo en: CABRERA, M y SÁNCHEZ, J., 2007. Unapropuesta de financiación municipal.Documento de Trabajo no 28/07 del IEF., p.1-63.
} 
Los cambios legislativos se realizaron a través de la Ley 13/1996, que estableció una serie de normas orientadas hacia la consecución del saneamiento de las cuentas municipales, que modificaban reglas de la LRHL, como un nuevo cálculo de la carga financiera, nuevas limitaciones al endeudamiento local etc. Más adelante, la Ley 66/1997, añadió medidas en relación al control e información por parte del Ministerio de Economía y Hacienda. La Ley 50/1998, modificó el capítulo IV de la Ley 39/1988, Reguladora de las Haciendas Locales (en adelante LRHL) y la Ley 55/1999, modificó algunos artículos de la Ley 7/1985, de 2 de abril, Reguladora de las Bases de Régimen Local, en lo que a competencia se refiere, mientras el artículo 56 de la LRHL fue modificado por la Ley 14/2000. Por último, la Ley 51/2002, de 27 de diciembre, de reforma de la Ley 39/1988, de 28 de diciembre, reguladora de las Haciendas Locales, introduce novedosas modificaciones en el ámbito de la financiación local, tanto desde el punto de vista puramente económico como desde el punto de vista financiero y el Real Decreto Legislativo 2/2004, recoge en un texto refundido la Ley Reguladora de las Haciendas Locales, dedicando el capítulo VII a la regulación de las operaciones de crédito de las Entidades locales.

En los últimos tiempos, los Ayuntamientos españoles han asumido una deuda pública local considerable debido en parte a la gran demanda social que ha tenido que asumir, fundamentalmente en el plano de la construcción y en la inversión de equipamientos en todos los ámbitos. Además, los Ayuntamientos españoles deben cumplir los compromisos que se derivan del pacto de estabilidad de la Unión Europea. Por ello, en la actualidad, a la hora de adoptar decisiones financieras profesionales en las Entidades locales, la gestión ${ }^{5}$ del endeudamiento ha pasado a ocupar un papel de gran importancia, como pone de manifiesto Farfán ${ }^{6}$, quien añade que tiene que tenerse en cuenta la dificultad que implica la gestión de la Tesorería ${ }^{7}$ y del Endeudamiento, como consecuencia de las innovaciones introducidas, tanto en productos, como en mercados financieros, y la necesidad de diversificar riesgos financieros, que no se encuentra circunscrita a este aspecto de gestión simplemente. Asimismo, la normativa aplicable desempeña un papel fundamental en la toma y ejecución de decisiones financieras, ya que viene a determinar las reglas de actuación en el proceso de gestión.

Actualmente, el crédito local se encuentra regulado en el Capítulo VII del Libro Primero del Real Decreto Legislativo 2/2004, de 5 de marzo, bajo la rúbrica "Operaciones de Crédito".

Fruto de la necesidad de un mayor control del endeudamiento de las Administraciones Públicas, y por tanto, del local, existe una creciente restricción desde la redacción originaria de la LRHL y la normativa reguladora establece una serie de requisitos y de limitaciones en el momento de concertar operaciones de crédito, que son:

a) Inclusión de las operaciones de crédito en el presupuesto aprobado, aunque excepcionalmente se podrán concertar operaciones de crédito cuando se produzca la situación de prórroga del presupuesto.

b) Informe previo de intervención, en el que se analizará especialmente la capacidad de la entidad local para hacer frente, en el tiempo, a las obligaciones que de ellas se deriven para ésta.

c) Especial referencia a las operaciones de crédito a corto plazo siempre que se cumplan determinados requisitos ${ }^{8}$. La finalidad de recurrir a éste tipo de operaciones de crédito es

\footnotetext{
${ }^{5}$ Entre lasdistintasformas de gestiónencontramos la gestiónfinancieraquees la quealude de manera general al dinero en todas sus acepciones. Para algunosautoresesimprescindible en cualquierentidadquemanejeunpresupuesto. La gestiónfinancieraengloba la gestión de la tesorería y la gestióndelendeudamiento.

${ }^{6}$ FARFÁN, J. M., 2001. Consideraciones del modelo legal de endeudamiento de lasEntidades Locales.El Consultor de los Ayuntamientos y de los Juzgados, $\mathrm{n}^{\circ}$ 7, p. 1168.

7 La tesoreríaesdefinidacomo la capacidadquetiene la empresapara, con el dineroefectivo y lasdeudas a cortoplazopendientes de cobro, poderhacerfrente a lasdeudas a cortoplazo.

${ }^{8}$ Contemplados en el artículo 51 del TRLRHL y referidos a o siguiente: - que tenga por finalidad atender necesidades transitorias de tesorería,
} 
atender necesidades transitorias de Tesorería, déficits temporales de liquidez ${ }^{9}$ derivados de las diferencias de vencimientos entre los pagos y los ingresos en la gestión de la Tesorería, como así lo establece el artículo 199 del TRLRHL. Autorizaciones para la concertación de operaciones de crédito a largo plazo ${ }^{10}$ que surgen con la finalidad de financiar inversiones. En este sentido es necesario diferenciar entre el régimen general y el régimen especial referido a las entidades locales con más de 20.000 habitantes.

d) Límites máximos que podrán fijar anualmente las Leyes de Presupuestos Generales del Estado.

e) Información al Ministerio de Hacienda y a la Central de Información de riesgo del Ministerio que provea de información sobre las distintas operaciones de crédito concertadas por las entidades locales y las cargas financieras que supongan a la cual deben remitir la información de que dispongan los bancos, cajas de ahorro y demás entidades financieras, así como las distintas Administraciones Públicas.

Como apuntan López y De los Ríos ${ }^{11}$, la mayoría de Entidades locales, obtienen sus recursos principalmente de las entidades financieras en forma de préstamos, y dentro de éstos, la mayor importancia relativa la tienen los concertados a medio y largo plazo ${ }^{12}$.

\section{ESPECIAL REFERENCIA A LAS ALTERNATIVAS AL ENDEUDAMIENTO}

La ley 18/2001, de 12 de diciembre, General de EstabilidadPresupuestaria, establecía la obligacióntodos los estratos de la Administraciónpública de conservar la estabilidadpresupuestaria, estoes, quesuscuentasreflejenequilibrio o superávit. Dicha Ley, ha sidoderogadapor el Real DecretoLegislativo 2/2007 ${ }^{13}$, - quetambiénderoga la Ley 15/2006, de 26 de mayo quereformaba la Ley 18/2001 - y quetieneporfinalidadincrementar la claridad del sistema de disciplina fiscal y de gestiónpresupuestaria. Actualmente, la Ley vigentees la Ley 2/2012, de 27 de abril, de EstabilidadPresupuestaria y SostenibilidadFinanciera.

La limitaciónestablecida a la posibilidad de elevarindiscriminadamente el endeudamientopor parte de lasentidades locales y lasdificultadesactualesporlasqueatraviesas los municipiosespañolesderivadas de la crisis económicaprincipalmente, noshaceplantearnos la necesidad de pensar en otrasalternativasdistintas, tales comolasanalizadas a continuación ${ }^{14}$ :

\footnotetext{
- que el plazo de vencimiento no exceda de un año

- que en su conjunto, la deuda total a corto plazo, no supere el 30 por ciento de sus ingresos liquidados por operaciones corrientes en el ejercicio anterior, salvo que la operación haya de realizarse en el primer semestre del año sin que se haya producido la liquidación del presupuesto de tal ejercicio, en cuyo caso se tomará en consideración la liquidación del ejercicio anterior a este último.
}

${ }^{9}$ La falta de liquidez de los Ayuntamientos y el alto nivel de endeudamiento actual obligan a los responsables de los mismos a manejarlasreglasdelSistemaFinanciero.

${ }^{10}$ En estamismalínea, intentandolimitar el accesoporlasentidades locales al endeudamientopúblico, el artículo 53 del TRLHL fija un régimen de autorizacionesexternas (por los órganoscompetentes del Ministerio de Hacienda), para la concertación de operaciones de crédito a largo plazocuando se produzcanunaserie de circunstancias, quehansidotratadasporVallés y otros en:

VALLÉS, J. PASCUAL, P. Y CABASÉS, F., 2005. "Un análisis con microdatos de la normativa de control del endeudamiento local. Papeles de TrabajodelInstituto de EstudiosFiscales. SerieEconomía ISSN 1578-0252, nº8, p. 551.

11 LÓPEZ, M.C. y DE LOS RÍOS, A., 2003. "Estabilidadpresupuestaria y endeudamiento de lasadministracionesterritoriales".Revista de EstudiosRegionales no 66, p. 289-305.

${ }^{12}$ Así, en el estudio realizado por las autoras reseñadas se pone de manifiesto que en el período comprendido desde 1995 hasta 2001, se produjo un aumento del saldo vivo de la deuda total local cercano al 16\%, lo que supone aproximadamente un promedio anual del 2,5\%.

${ }^{13}$ de 28 de diciembre, por el que se aprueba el texto refundido de la Ley General de Estabilidad Presupuestaria.

14 Un mayor desarrollo en: VALLECILLO F., 2005. Ahorro y estabilidad. Nueva visión de un Presupuesto Municipal. El Consultor de los Ayuntamientos y de los Juzgados no 3, p. 379.

Revista de Direito Brasileira | São Paulo, SP | v. 20 | n. 8 | p. 320-335 |Mai./Ago. 2018 
1) Alternativa 1: Incremento de la presión fiscal.

2) Alternativa 2: Eliminar determinados servicios.

3) Alternativa 3: Sociedades mercantiles.

4) Alternativa 4: Sociedad operadora que preste el servicio.

5) Alternativa 5: Concesión de obra y servicio.

6) Alternativa 6: El arrendamiento.

7) Alternativa 7: Leasing, renting y confirming.

8) Alternativa 8: Project finance.

9) Alternativa 9: Titulización.

10) Alternativa 10: La solución digital.

11) Alternativa 11: Legalización de infracciones urbanísticas.

12) Alternativa 12: La contratación público-privada.

13) Alternativa 13: Reducción de la facturación de los contratos.

14) Alternativa 14: Medidas en relación al personal.

Veamos brevemente cada una de ellas.

1) Alternativa 1: Incremento de la presión fiscal.La presión fiscal es el indicador que mide la participación de los ingresos fiscales de todas las Administraciones Públicas sobre el Producto Interior Bruto (PIB).

La elevación de la presión fiscal se presenta como la fórmula más cómoda, ya que implica directamente un incremento en los ingresos corrientes locales, siempre que su aprobación se produjere antes de la entrada en vigor del devengo impositivo (esto es, se debe prever la oportuna publicación definitiva y entrada en vigor de la modificación de la ordenanza fiscal correspondiente, normalmente antes del día 1 de enero del año en cuestión). Ahora bien, esta solución no es deseable políticamente, ya que se trata de una medida "impopular".

A este inconveniente se une la modificación del Impuesto sobre Actividades Económicas desde 2003, que ha sido determinante de la elevación por la mayoría de los Ayuntamientos de los tipos impositivos del Impuesto sobre Bienes Inmuebles para paliar la pérdida de recaudación (a pesar de la compensación estatal de las pérdidas derivadas del Impuesto sobre Actividades Económicas). Así pues, tras esta subida impositiva en 2003 y 2004, parece difícil que las Entidades locales quieran, políticamente, una mayor presión fiscal.

2) Alternativa 2: Eliminar determinados servicios.Otra fórmula también cómoda técnicamente es eliminar gastos del capítulo 2 de bienes corrientes y servicios, reduciendo la prestación de servicios. En este caso, estamos ante una medida políticamente no operativa, pues en la práctica se ha comprobado que cualquier ahorro conocido en un gasto corriente se ha empleado para prestar otros servicios, resultando que al final del año presupuestario los gastos del capítulo 2 han ido creciendo. Por lo que respecta a los gastos, los municipios están obligados a prestar unos determinados servicios, en función del número de habitantes, como así lo dispone la Ley 7/1985, de 2 de abril, reguladora de las Bases de Régimen Local. No obstante, se permite una total discrecionalidad a la hora de prestar más servicios que los obligados por la LRBRL, incluso en cuanto a la calidad de los servicios que debe prestar como mínimos y obligatorios.

3) Alternativa 3: Sociedades mercantiles.En virtud de lo establecido en los artículos 49.1 y 53.1 del TRLHL, para la financiación de sus inversiones, las Entidades locales, sus organismos autónomos y los entes y sociedades mercantiles dependientes, que prestan servicios o produzcan bienes que no se financien mayoritariamente con ingresos de mercado, 
podrán acudir al crédito público y privado, a largo plazo, en cualquiera de sus formas. Asimismo, el artículo 85 de la LRBRL, por su parte,viene a regular las distintas formas de prestar los servicios, bien por gestión directa o indirecta, entre las que se incluye a las sociedades mercantiles. Ahora bien, para la articulación de la posibilidad de optar por parte de estas sociedades municipales de endeudarse para la financiación de sus inversiones, las denominadas «dependientes» deberán atenerse a los criterios señalados en los artículos 48 a 55 del TRLHL, relativo a operaciones de crédito, y será por lo tanto considerado endeudamiento local.

4) Alternativa 4: Sociedad operadora que preste el servicio. En este supuesto es necesaria la presencia de una sociedad que se encargue de la construcción y explotación de la infraestructura, siendo la sociedad la que, generalmente, haya de endeudarse y, con los precios que perciba del usuario de la infraestructura, hacer frente a la carga financiera y a los gastos de la explotación y a su vez, obtener un beneficio.

Si la sociedad es una unidad institucional orientada al mercado, su endeudamiento no será considerado endeudamiento del sector público local en términos del SEC-95 cuando sus ingresos por ventas sean superiores a la mitad de los costes de producción.

La sociedad operadora es pública, y en todo caso mixta, y en este último caso es donde hay que seleccionar al socio privado.

De este modo, la gestión del servicio permanece en la esfera pública, lo que puede ser una ventaja «política» en determinadas circunstancias.

5)Alternativa 5: Concesión de obra y servicio.En la concesión, - caracterizada por, entre otras notas, el riesgo concesional, el equilibrio económico de la concesión, y la diversificación de la financiación - la Administración encarga a un tercero la ejecución de una obra pública, siendo la contraprestación del contratista el derecho que se le reconoce de explotar la obra construida durante cierto período de tiempo. Las ventajas son claras, pues resuelve la financiación, la explotación y el mantenimiento de la infraestructura. Sin embargo, el inconveniente es que su uso está limitado a infraestructuras susceptibles de explotación económica que sean atractivas para el sector privado.

6)Alternativa 6: El arrendamiento. A través del contrato de arrendamiento (o locatioconductio por su denominación originaria en latín), una de las partes, llamada arrendador, se obliga a transferir temporalmente el uso y goce de una cosa mueble o inmueble a otra parte denominada arrendatario, quien a su vez se obliga a pagar por ese uso o goce un precio cierto y determinado, dinerario o en especie.

Cualquier empresa, y por supuesto también la Administración Pública, ante un gasto importante de adquisición de un activo, se plantea la opción de comprar o alquilar. Pero es más, siendo imposible adquirir el activo con medios propios, y no pudiendo acudir al endeudamiento, el alquiler se presenta como una solución a tener en cuenta.

En este caso, la titularidad de las infraestructuras corresponde a la empresa que arrienda, incrementándose el capítulo 2 del presupuesto de gastos de la Entidad local por la parte correspondiente al alquiler durante una serie de años. Así, pese a no tener que buscar financiación para la construcción, sí será necesario obtener financiación para el alquiler.

7) Alternativa 7: Leasing, renting y confirming.Estos términos anglosajones, tan usuales en nuestra terminología local, han tenido una regulación reciente para darle cabida legislativa a prácticas habituales de mercado.

El leasing y renting para las inversiones y el confirming para el circulante, se presentan como una auténtica alternativa al endeudamiento, especialmente para una aplicación real de 
sincronización en tiempos de la amortización técnica del bien con la amortización financiera, pues no tiene sentido financiar unos equipos informáticos con un préstamo a 15 años.

El leasing financiero es un arrendamiento financiero de inmuebles o bienes de equipo, con una opción de compra por un valor simbólico al término del contrato. Habitualmente, la opción de compra final, suele ser una cuota más; es una opción de compra alejada del valor residual y, en términos SEC-95, debe computar como endeudamiento, pues de la lectura del Reglamento de la Unión Europea SEC-95 se desprende que cuando en el leasing financiero, la opción de compra no es más que una cuota simbólica, lo que se ha realizado es un pago aplazado o financiado, y por lo tanto debe considerarse endeudamiento.

El leasing operativo es un arrendamiento financiero de bienes de equipo con una opción de compra aproximadamente igual al valor de mercado del bien arrendado al término del contrato, pudiendo incluir algunos servicios complementarios tales como mantenimiento, repuesto y seguros. Como la opción de compra es «real e importante» y no una cuota más, no computa como endeudamiento en términos SEC-95.

El renting es un arrendamiento, conocido en el mercado de los vehículos, pero también en cualquier bien de equipo, sin opción de compra, con una prestación de servicios muy significativos entre los que figuran el mantenimiento, los seguros y los consumibles. El conocimiento de las cuotas a pagar mensuales tiene el beneficio de poder planificar la tesorería, y contar con unos bienes renovados y actualizados. La opción por el rentingno va a incrementar el endeudamiento, pero sí es mayor el gasto corriente.

Por lo que respecta al confirming, es un servicio consistente en gestionar los pagos que las Corporaciones locales (o cualquier empresa), realizan a sus proveedores, con la posibilidad de anticipar a los mismos el cobro de sus facturas. No se refiere a la financiación de las inversiones pero sí del circulante, siendo una medida previa a una operación a corto plazo.

8) Alternativa 8: Project finance. El Project Finance o financiación de proyectos ${ }^{15} \mathrm{o}$ finanproyecto (traducción adaptada del vocablo inglés) es un mecanismo de financiación de inversiones de gran envergadura que se sustenta tanto en la capacidad del proyecto para generar flujos de caja que puedan atender la devolución de los préstamos como en contratos entre diversos participantes que aseguran la rentabilidad del proyecto. Asimismo, son proyectos caracterizados por incluir tecnologías ampliamente maduras.

El finanproyectoesunatécnica de usogeneralizado en la implantación del sector de telecomunicaciones (telefoníamóvil, televisiónpor cable, etc.). Sin embargo, en la actualidad, ha tomadomuchafuerza en sectorescomo el eléctrico o del transporte, permitiendodesplazarestasgrandesinversiones, históricamenteunidas al sector público, hacia el sector privado. Másconcretamente, grandesparquesfotovoltaicos y eólicos son financiadosmedianteestamodalidad, pues la propianaturaleza de estetipo de proyectos se adaptaplenamente a la filosofía del Project Finance, y la legislación actual permiteasegurarunageneración de flujosprevisible y suficientequesostenga el pago de lascuotascrediticias.

La operatoria consiste en una sociedad gestora que se hace cargo de la construcción de una infraestructura, y que es ella la que se endeuda, y que, con los ingresos de la explotación del servicio, cubre los gastos de la explotación, la amortización de la deuda, y la obtención de beneficios para la propia entidad.

9) Alternativa 9: Titulización.La titulización puede definirse, como un mecanismo para la transformación de los activos tradicionales reflejados en el balance de una entidad en valores susceptibles de ser negociados en mercados secundarios. Estos valores facilitan el acceso a

\footnotetext{
${ }^{15}$ Véase: CARBONERO MANRIQUE, J.A. "La Financiación de un PPP: El Project Finance", Revista de Estudios Locales, Cunal, n. ${ }^{\circ} 132,2010$, p. 90-127.
}

Revista de Direito Brasileira | São Paulo, SP | v. 20 | n. 8 | p. 320-335 |Mai./Ago. 2018 
financiación para su emisor, o más bien el "generador", mediante el especial vehículo conocido como fondo de titulización. A cambio, los flujos de caja cedidos al fondo se mantienen ajenos a los procedimientos concursales debido a la naturaleza aislada del fondo mismo.

La titulización de activos consiste en transformar cualquier activo susceptible de generar rendimientos (normalmente derechos de cobro futuros) en títulos o valores negociables en mercados organizados. Lógicamente, los derechos de cobro susceptibles de titulización serán aquellos que sean seguros y estables en el tiempo, por ejemplo, los préstamos hipotecarios de una entidad bancaria concedidos a particulares, los peajes cobrados por una compañía de autopistas o los recibos de una eléctrica. No obstante, en última instancia todo depende de la confianza de los inversores.

La titulización también sirve para financiar de forma privada grandes proyectos públicos. Así, como ejemplo de la aplicación en el sector local son las iniciativas para titulizar los derechos de crédito del concesionario de infraestructuras.

En todo caso, el nivel alcanzado por la titulización en España está aún lejos del logrado por otros países europeos.

10) Alternativa 10: La solución digital.En un contexto de crisis económica, es fundamental el uso de las Tecnologías de la Información y la Comunicación (en adelante, TIC) para ayudar a salir de la crisis y volver a alcanzar el crecimiento y la sostenibilidad económica. Las TIC posibilitan absoluta publicidad y transparencia de todos los costes que resulten de la gestión pública.

Actualmente, el uso de las TIC se ha generalizado en España, incluso en el ámbito de los trámites con lasAdministracionesPúblicas. La extensión de las TIC a todos los territorios forma parte de la agenda de Gobiernos e instituciones de todo el mundo.

La utilización de las TIC supone, portanto, unahorropara el administrado, perotambién la Administraciónelectrónicaahorradinero. Porponerunejemplo, se ahorraríamuchísimodinero en fotocopias. La forma de implantar la Administraciónelectrónicaesmediante la previaplanificación. La licitaciónelectrónicatambiénesmáseconómica y ademássalvaguarda los principios de eficacia, igualdad, concurrencia y, principalmente, el de objetividad.

Los beneficiosquepuedesuponerparalasEntidades locales, tantomediante la implantación del registroelectrónico, como a través del tablón de anuncioselectrónico, la tramitacióninformatizada de licencias, la contrataciónelectrónicao la carpetaciudadana, porponeralgunosejemplospuedensuponerunareducciónimportante de los gastos de la Entidad local ${ }^{16}$.

11) Alternativa 11: Legalización de infracciones urbanísticas.El descenso producido en el sector de la construcción es hoy en día una de las principales causas de la crisis, debido al descenso de ingresos en las entidades locales, puesto que descienden las liquidaciones de las tasas por licencia de obras y del Impuesto sobre Construcciones, Instalaciones y Obras.

Lo que se propone con estaalternativaescontrolar y comprobarlasinfraccionesurbanísticasque no esténprescritas, y al mismotiempoqueseanlegalizables, o quequepareposición de la legalidad, paraexigir la liquidación de la tasaporlicencia de obras y el ImpuestosobreConstrucciones, Instalaciones y Obras, asícomolasposiblessancionesque se puedanimponer y de estemodoobtenerliquidez, pues se incrementarían los ingresos del ente local.

Con estamedida se pretende no solo recaudar, sinopreservar la legalidad de aquellasinfracciones no prescritas.

12) Alternativa 12: La contratación público-privada. La contratación público-privada se presenta como un instrumento eficaz en época de insuficiencia de recursos, ya que mediante esta fórmula se obtiene liquidez y se mejora la gestión. En el contexto actual, es cada vez más necesario encontrar fórmulas de colaboración con el sector privado y la colaboración público-

\footnotetext{
${ }^{16}$ Véase:

- SALGADO, R., 2011. «iMásAdministraciónelectrónica. Estoes la crisis!», Revista de Estudios Locales, n. ${ }^{\circ}$ 142, p. 96-109.

PORTILLO, M.J. y MERINO, V., 2012 (Coord). Crisis económica y entidades locales. Valladolid. Lex Nova, p. 59-92.
}

Revista de Direito Brasileira | São Paulo, SP | v. 20 | n. 8 | p. 320-335 |Mai./Ago. 2018 
privada $^{17}$ se convierte en una fórmula para poder seguir prestando determinados servicios con la ayuda o inversión del sector privado. No obstante, esta figura debe ser utilizada con carácter excepcional.

El inicio de la contratación público-privada en España, lo podemos situar con el desarrollo de autopistas de peaje.

13) Alternativa 13: Reducción de la facturación de los contratos.La contratación pública es una actividad económica importante en España.

Se trata de una nueva política o actividad de fomento de las Administraciones Públicas, mediante la cual se dirige la actividad privada al logro de unos concretos objetivos, principalmente de rentabilidad económica, como un motor de la economía que usa como combustible la innovación.

En materia de contratación, también hay que destacar la Directiva 2004/18/CE del Parlamento Europeo y del Consejo de 31 de marzo de 2004 sobre coordinación de los procedimientos de adjudicación de los contratos públicos de obras, de suministro y de servicios, que en su artículo 1.2.a) dispone: «Son contratos públicos los contratos onerosos y celebrados por escrito entre uno o varios operadores económicos y uno o varios poderes adjudicadores, cuyo objeto sea la ejecución de obras, el suministro de productos o la prestación de servicios en el sentido de la presente Directiva». A tenor de lo expuesto, se puede constatar que dos o más Ayuntamientos pueden unirse para licitar un mismo servicio, en una suerte de licitación conjunta, como así ha ocurrido en algunas ocasiones, lo cual puede reducir el gasto local.

14) Alternativa 14: Medidas en relación al personal.Una de las alternativas a la disminución del endeudamiento es la referida a la reducción de gastos de personal, los cuales representan, en la mayoría de los municipios, más de un tercio del gasto total. A continuación, vamos a analizar una serie de medidas que favorezcan el ahorro de costes en materia de personal.

Se puede adoptar como medida en los Ayuntamientos la reducción de personal laboral temporal, que obedece a servicios no necesarios, realizando para ello un análisis exhaustivo de la relación de puestos de trabajo, valorando además la supresión de plazas prescindibles para no sacarlas a concurso. Asimismo, pueden reducirse plazas de jefatura creando áreas, que agrupen varias, gestionadas por un único técnico, que aunque tendrá una mayor retribución, supone un ahorro en comparación con el resto de trabajos que se fusionan en uno sólo.

Del análisis de esta relación de puestos de trabajo, se pueden adoptar medidas como la revisión de las funciones de todo el personal, para llevar a cabo la máxima expresión del principio de eficiencia. Como consecuencia de esta revisión, puede llevarse a cabo una reasignación de efectivos así como prever las plazas cuyo titular esté en situación de jubilación, por lo que debería procederse a la amortización de esos puestos de trabajo.

Una fórmula alternativa a la contratación temporal, sería la utilización de los convenios de colaboración social.

A esta alternativa a la contratación temporal, se sumarían, los trabajos en beneficio de la comunidad, que es un servicio, casi sin coste.

Otra medida en materia de personal sería llevar a cabo un control de las horas extra, principalmente de aquellos colectivos que más perciben este tipo de complementos como ocurre en todas o la mayoría de entidades locales, con los cuerpos de la policía local.

\footnotetext{
${ }^{17}$ Para másinformación, véase:

- SUÁREZ PANDIELLO, J. y FERNÁNDEZ LLERA, R. Impactos de la crisis sobre la Hacienda local española: Datos y retos básicos. En: PORTILLO NAVARRO, M.J. y MERINO ESTRADA, V. (Coord). Crisis económica y entidades locales. Valladolid, Lex Nova, 2012, p.59-92.

- GABILANES GINERÉS, G.M. «Presente y futuro de la colaboraciónpúblicoprivada en España», Revista de ObrasPúblicas, n. ${ }^{\circ} 3.425,2002$, p. 213-222.
}

Revista de Direito Brasileira | São Paulo, SP | v. 20 | n. 8 | p. 320-335 |Mai./Ago. 2018 
Otramedida en materia de personal, queya se ha contempladolegalmente, es la relativa a la bajada de sueldo de los funcionarios.Así en el año 2012, los gastos de personal funcionario, se redujeron en un 3,3porcien.

En el siguientecuadropodemosver los gastosdelcapítulouno de los presupuestos de los municipios, relativo a los gastos de personal en los años 2004 a 2012.

Cuadro II. Liquidación de Presupuestos de entidades locales. Gastos de personal y endeudamiento. Miles de euros y porcentajes. Años 2004-2012.

\begin{tabular}{|l|l|l|l|l|l|l|l|}
\hline \multicolumn{1}{|c|}{ AÑ OS } & $\begin{array}{c}\text { CAPÍTULO } \\
\text { 1 DE } \\
\text { GASTOS }\end{array}$ & $\begin{array}{c}\text { CTO } \\
\text { C.1 }(\boldsymbol{\%})\end{array}$ & $\begin{array}{c}\text { CAPÍTULO } \\
\text { 9 DE } \\
\text { INGRESOS }\end{array}$ & $\begin{array}{c}\text { CTO } \\
\text { C.9 } \\
(\%)\end{array}$ & $\begin{array}{c}\text { TOTAL } \\
\text { GASTOS }\end{array}$ & $\begin{array}{c}\text { CTO } \\
\text { TOTAL } \\
(\%)\end{array}$ & $\begin{array}{c}\text { C. 9/C.1 } \\
(\%)\end{array}$ \\
\hline $\mathbf{2 0 0 4}$ & 14.184 .240 & & 4.339 .792 & & 53.604 .805 & & 30,6 \\
\hline $\mathbf{2 0 0 5}$ & 15.301 .521 & 7,9 & 3.964 .181 & $-8,7$ & 58.072 .897 & 8,3 & 25,9 \\
\hline $\mathbf{2 0 0 6}$ & 16.568 .857 & 8,3 & 3.751 .258 & $-5,4$ & 65.463 .431 & 12,7 & 22,6 \\
\hline $\mathbf{2 0 0 7}$ & 18.087 .293 & 9,2 & 3.503 .264 & $-6,6$ & 71.702 .611 & 9,5 & 19,4 \\
\hline $\mathbf{2 0 0 8}$ & 19.553 .949 & 8,1 & 4.277 .098 & 22,1 & 74.862 .314 & 4,4 & 21,9 \\
\hline $\mathbf{2 0 0 9}$ & 20.669 .268 & 5,7 & 6.285 .814 & 47,0 & 79.391 .283 & 6,0 & 30,4 \\
\hline $\mathbf{2 0 1 0}$ & 20.479 .571 & $-0,9$ & 4.951 .023 & $-21,2$ & 76.369 .284 & $-3,8$ & 24,2 \\
\hline $\mathbf{2 0 1 1}$ & 20.098 .645 & $-1,9$ & 2.790 .018 & $-43,6$ & 69.718 .844 & $-8,7$ & 13,9 \\
\hline $\mathbf{2 0 1 2}$ & 18.283 .623 & $-9,0$ & 9.995 .265 & 258,3 & 65.641 .831 & $-5,8$ & 54,7 \\
\hline MEDIA & 18.136 .330 & 3,0 & 4.873 .079 & 26,9 & 68.314 .144 & 2,5 & 26,9 \\
\hline $\begin{array}{l}\text { CTO 2004- } \\
\mathbf{2 0 1 2}\end{array}$ & & & & & & 22,5 & \\
\hline
\end{tabular}

Fuente: Ministerio de Hacienda y AdministracionesPúblicas y elaboraciónpropia.

Como podemos observar en el cuadro, los gastos de personal del capítulo uno de las Entidades locales, han ido aumentando año tras año hasta 2009, en el que empiezan a descender, año en el que ya estaba afianzada la crisis económica.

Por lo que respecta a los pasivos financieros del capítulo nueve de ingresos vemos que con los ingresos que se obtienen de la concertación de operaciones de crédito no se puede hacer frente a los gastos de personal. La cuantía de los mismos presenta oscilaciones a lo largo de los años y en el año 2011, su cuantía se redujo drásticamente, motivada por las limitaciones para la concertación de operaciones de crédito, si bien en 2012 el crecimiento fue espectacular: un 258,3 por cien con respecto al año anterior.

Las tasas de variación anuales del total de gastos de las Entidades locales (obligaciones reconocidas) han seguido un patrón de crecimiento similar al de los gastos de personal, ya que presentan tasas positivas hasta 2009 y, a partir de este año, las tasas son negativas, pues se reduce el gasto total de las Entidades locales.

La reducción del gasto de personal puede suponer una disminución del endeudamiento local, en tanto que estas cantidades se podrían utilizar para otras necesidades. Por ello, hemos realizado una proyección de la reducción del endeudamiento que se produciría en diversos escenarios de reducción del gasto de personal. Dado que el endeudamiento presenta grandes oscilaciones en los últimos años, hemos optado por utilizar los datos correspondientes a la media del período analizado en el cuadro precedente. Los resultados obtenidos se muestran en el siguiente cuadro. 
Cuadro IV. Proyección de lareducción de los gastos de personal y elendeudamiento. Porcentajes. Año 2011.

\begin{tabular}{|l|l|}
\hline REDUCCIÓN CAP. 1 & REDUCCIÓN CAP. 9 \\
\hline $1 \%$ & $3,72 \%$ \\
\hline $2 \%$ & $7,44 \%$ \\
\hline $3 \%$ & $11,17 \%$ \\
\hline $4 \%$ & $14,89 \%$ \\
\hline $5 \%$ & $18,61 \%$ \\
\hline $10 \%$ & $37,22 \%$ \\
\hline
\end{tabular}

Fuente: Ministerio de Hacienda y AdministracionesPúblicas y elaboraciónpropia.

La reducción del 1 por cien del gasto en personal supone la disminución del 3,72 por cien del endeudamiento de ese año y si consideramos una reducción del 5 por cien del gasto en personal de las Entidades locales, se podría disminuir el 18,61 por cien el endeudamiento. Por último, si la reducción del capítulo uno fuera del 10 por cien, el endeudamiento se podría reducir en un 37,22 por cien. Este análisis debería ser considerado por los gestores locales para mejorar la gestión del endeudamiento.

Todas las alternativas planteadas en el presente capítulo son susceptibles de mejora, modificación y ampliación e incluso agrupación, pues las entidades locales pueden llevar a cabo algunas de ellas o varias. En cualquier caso, solamente pretenden ser vías para abrir el debate en torno a la necesidad de reducir el endeudamiento por parte de las Entidades locales, al menos hasta que la situación económica mejore de manera sostenible y las Entidades locales puedan obtener mayores ingresos o que se lleve a cabo la tanta veces pretendida y nunca realizada, reforma de la financiación local.

\section{CONCLUSIONES}

Tras la exposición realizada queda de manifiesto la gran importancia de una adecuada planificación, ya que la formación de un presupuesto municipal para todo un ejercicio económico tiene que ser un análisis pormenorizado y es una limitación para los gastos, puesto que la elaboración del documento presupuestario es política y técnica y todas aquellas cuestiones que no estén previstas supondrán problemas a los que hacer frente a lo largo del ejercicio presupuestario.

Asimismo, se desprende la necesidad de adaptación al cambio. Con este trabajo se puede observar cómo las nuevas restricciones al crecimiento del endeudamiento del sector público local, han favorecido la utilización de nuevas técnicas financieras para poder seguir gestionando y aumentando la prestación de servicios públicos. El sector privado y la banca ofrecen nuevas posibilidades de financiación que es necesario conocer detalladamente para su posible utilización.

En principio, el recurso al endeudamiento no es una opción desacertada, ya que posibilita mantener los recursos propios a cambio de recursos ajenos para hacer frente a nuevos bienes y servicios. No obstante, se convierte en una pésima opción cuando no es utilizado para el fin real para el que fue solicitado o bien cuando se recrudecen las condiciones de devolución, convirtiéndose de éste modo en uno de los motivos para el subdesarrollo más que una vía para solucionarlo.

Un gran endeudamiento puede acarrear la imposibilidad de obtener nuevos créditos en caso de necesidad. Normalmente, si la deuda es muy grande la entidad no es capaz de pagar ni los intereses, lo que conlleva que la deuda vaya creciendo con el tiempo, caminando en una espiral sin fin de empobrecimiento. Por lo tanto, debe acudirse al recurso al endeudamiento con cautela, 
puesto que si la entidad administrativa es ineficiente puede conllevar una lenta recuperación de lo invertido.

En la situación actual, en la cual la vía del endeudamiento local es la que están utilizando, dentro de los límites, muchos municipios para hacer frente a los gastos tras la brusca caída de los ingresos tributarios, existen otras alternativas - tal y como se muestra en el presente trabajo - que se plantean o se pueden plantear los municipios y que les pueden resultar de utilidad para el presente y el futuro.

\section{BIBLIOGRAFÍA}

CABRERA, M y SÁNCHEZ, J., 2007. Una propuesta de financiación municipal. Documento de Trabajo no 28/07 del IEF., p.1-63.

DOMÍNGUEZ-MACAYA, J., 2011. «De las palabras a los hechos: estudio del modelo vasco de contratación pública electrónica (MVCPE). Un modelo sencillo, disponible y seguro. Contratación Administrativa», La Ley, n. ${ }^{\circ}$ 113, p.50-63.

FARFÁN, J. M., 2001. Consideraciones del modelo legal de endeudamiento de las Entidades Locales. El Consultor de los Ayuntamientos y de los Juzgados, nº 7, p. 1168.

LÓPEZ, M.C. y DE LOS RÍOS, A., 2003. "Estabilidad presupuestaria y endeudamiento de las administraciones territoriales". Revista de Estudios Regionales n 66, p. 289-305.

PORTILlo, M.J. y MERINO, V., 2012 (Coord). Crisis económica y entidades locales. Valladolid. Lex Nova, p. 59-92.

VALLECILLO F., 2005. Ahorro y estabilidad. Nueva visión de un Presupuesto Municipal. El Consultor de los Ayuntamientos y de los Juzgados nº 3, p. 379.

VALLÉS, J. PASCUAL, P. Y CABASÉS, F., 2005. "Un análisis con microdatos de la normativa de control del endeudamiento local. Papeles de Trabajo del Instituto de Estudios Fiscales. Serie Economía ISSN 1578-0252, nº, p. 5-51. 